\title{
Quartz crystal microbalance assay of clinical calcinosis samples and their synthetic models differentiates the efficacy of chelation-based treatments
}

DOI:

10.1021/acsami.7b08423

\section{Document Version}

Accepted author manuscript

Link to publication record in Manchester Research Explorer

Citation for published version (APA):

Fei, F., Gallas, A., Chang, Y-C., Rao, Y., Hunter, A., Winpenny, R., Herrick, A., Lockyer, N., \& Blanford, C. F. (2017). Quartz crystal microbalance assay of clinical calcinosis samples and their synthetic models differentiates the efficacy of chelation-based treatments. ACS Applied Materials and Interfaces, 9(33), 27544-27552. https://doi.org/10.1021/acsami.7b08423

\section{Published in:}

ACS Applied Materials and Interfaces

\section{Citing this paper}

Please note that where the full-text provided on Manchester Research Explorer is the Author Accepted Manuscript or Proof version this may differ from the final Published version. If citing, it is advised that you check and use the publisher's definitive version.

\section{General rights}

Copyright and moral rights for the publications made accessible in the Research Explorer are retained by the authors and/or other copyright owners and it is a condition of accessing publications that users recognise and abide by the legal requirements associated with these rights.

\section{Takedown policy}

If you believe that this document breaches copyright please refer to the University of Manchester's Takedown Procedures [http://man.ac.uk/04Y6Bo] or contact uml.scholarlycommunications@manchester.ac.uk providing relevant details, so we can investigate your claim.

\section{OPEN ACCESS}


Subscriber access provided by The University of Manchester Library

Article

Quartz crystal microbalance assay of clinical calcinosis samples and their synthetic models differentiates the efficacy of chelation-based treatments

Fan Fei, Andrzej Gallas, Yun-Chuan Chang, Yikun Rao, Alan Christy Hunter, Richard

E. P. Winpenny, Ariane Herrick, Nicholas P. Lockyer, and Christopher Francis Blanford

ACS Appl. Mater. Interfaces, Just Accepted Manuscript • DOI: 10.1021/acsami.7b08423 • Publication Date (Web): 28 Jul 2017

Downloaded from http://pubs.acs.org on August 9, 2017

\section{Just Accepted}

"Just Accepted" manuscripts have been peer-reviewed and accepted for publication. They are posted online prior to technical editing, formatting for publication and author proofing. The American Chemical Society provides "Just Accepted" as a free service to the research community to expedite the dissemination of scientific material as soon as possible after acceptance. "Just Accepted" manuscripts appear in full in PDF format accompanied by an HTML abstract. "Just Accepted" manuscripts have been fully peer reviewed, but should not be considered the official version of record. They are accessible to all readers and citable by the Digital Object Identifier (DOI®). "Just Accepted" is an optional service offered to authors. Therefore, the "Just Accepted" Web site may not include all articles that will be published in the journal. After a manuscript is technically edited and formatted, it will be removed from the "Just Accepted" Web site and published as an ASAP article. Note that technical editing may introduce minor changes to the manuscript text and/or graphics which could affect content, and all legal disclaimers and ethical guidelines that apply to the journal pertain. ACS cannot be held responsible for errors or consequences arising from the use of information contained in these "Just Accepted" manuscripts. 


\begin{abstract}
This paper sets out in vitro protocols for studying the relative effectiveness of chelators used in the dissolution-based treatment of hard calcinosis. Pulverized hard calcinosis samples from human donors or synthetic hydroxyapatite nanoparticles were deposited by electrophoretic deposition on the surface of a quartz crystal microbalance sensor. Over 150 deposits of $<20 \mu \mathrm{g}$ were dissolved over the course of an hour by aliquots of buffered, aqueous solutions of two calcium chelators, EDTA and citrate, with the surface-limited dissolution kinetics monitored with $<1$ s time resolution. There was no statistically significant difference in dissolution rate between the four synthetic hydroxyapatite materials in EDTA, but the dissolution rates in citrate were lower for hydroxyapatite produced by acetate or nitrate metathesis. Hard calcinosis and synthetic hydroxyapatites showed statistically identical dissolution behavior, meaning that readily available synthetic mimics can replace the rarer samples of biological origin in the development of calcinosis treatments. EDTA dissolved the hydroxyapatite deposits more than twice as fast as citrate at $\mathrm{pH} 7.4$ and $37^{\circ} \mathrm{C}$, based on a first-order kinetic analysis of the initial frequency response. EDTA chelated 6.5 times more calcium than an equivalent number of moles of citrate. Negative controls using non-chelating $N, N, N^{\prime}, N^{\prime}$-tetraethylethylenediamine (TEEDA) showed no dissolution effect. Pharmaceutical dissolution testing of synthetic hydroxyapatite tablets over $6 \mathrm{~h}$ showed that EDTA dissolved 4-9 times more quickly than citrate.
\end{abstract}

\title{
Keywords
}

systemic sclerosis, scleroderma, calcinosis (cutis), soft-tissue calcification, QCM, EPD 


\section{Introduction}

Calcinosis (cutis) is a clinical problem characterized by sub-epidermal deposition of insoluble calcium salts such as carbonated hydroxyapatite. ${ }^{1}$ This soft-tissue calcification disorder often accompanies other rheumatic diseases, for example approximately $20-40 \%$ of patients with the multisystem connective tissue disease systemic sclerosis (SSc, also termed scleroderma) develop calcinosis. ${ }^{2-4}$ SSc-related calcinosis usually occurs over pressure points, for example, fingers, knees and elbows, and can cause considerable pain and function impairment. ${ }^{5}$ In addition, calcinotic lumps can become infected, especially when they ulcerate through skin. In these ways, calcinosis can have a major impact on quality of life.

Many different drugs and procedures have been reported as having some effectiveness in the treatment of calcinosis, but these have generally appeared in case reports, and none has been generally accepted as a standard therapy. ${ }^{1,6}$ The list includes surgical excision, laser ablation, and various drug-based therapies. ${ }^{5,7}$ The lack of effective treatments means that new approaches to therapy are urgently needed. Calcium chelators capable of dissolving calcinosis deposits present a promising alternative for drug development, especially if they could be delivered through application to skin. If welltolerated, such treatments hold potential to reduce or prevent disability, pain and ulceration associated with calcinosis, improving overall quality of life.

Despite the existence of safety concerns, ${ }^{8,9}$ chelators are widely used as antidotes for metal poisonings. ${ }^{10} \mathrm{Klein}$ et al. treated a patient with calcinosis by intravenous infusion of EDTA, and X-ray radiography results revealed marked diminution of the calcium deposits. ${ }^{11}$ Following that, various case reports showed similar efficacy of chelators in the treatment of calcinosis. ${ }^{12-15}$ More recently in a preliminary experiment, Lydon et al. re-emphasized that calcium chelators such as citric acid and EDTA can either effectively dissolve the calcinotic lumps or break them down into fine powders. ${ }^{16}$ Even at physiological $\mathrm{pH}$ values, calcium chelators such as citric acid and EDTA have strong chelation effect. ${ }^{17}$

Unfortunately, in vitro screening for dissolution performances of calcium chelators as potential treatments for calcinosis is complicated. Due to the rarity of the condition, the supply of calcinotic deposits is limited, hindering the number of experimental repeats. Also, the morphology, chemical composition, and crystal structure of SSc-related calcinotic deposits are heterogeneous. The chemical composition of calcinotic deposits is mainly hydroxyapatite (HAp, $\left.\mathrm{Ca}_{10}\left(\mathrm{PO}_{4}\right)_{6}(\mathrm{OH})_{2}\right)$ with some inorganic carbonates. ${ }^{18,19}$ Inconsistent surface areas and physicochemical properties of the deposits may therefore additionally complicate analysis and interpretation of in vitro dissolution studies, if performed using human samples. To this end, the field requires the development of an analytical method that uses a synthetic mimic for hard calcinosis (Supplementary Information, SI Fig. S1) with consistent physicochemical properties; enables quantitative measurement of in vitro pharmacodynamic chelator performances; and is amenable to automation and high-throughput screening approaches. Although macroscopic methods (e.g., rotating disk, ${ }^{20}$ powder suspension, ${ }^{21}$ and constant composition method ${ }^{22}$ ) might mimic real calcinosis dissolution to a first approximation, a microscopic method is warranted given the shortage of calcinosis samples.

In this work, we apply a quartz crystal microbalance with dissipation monitoring (QCM-D) to study the dissolution process with sub-second time resolution and high areal mass precision (ca. $0.5 \mathrm{ng} \mathrm{cm}{ }^{-2}$ in liquids). ${ }^{23}$ For comparison, a $1 \mathrm{~nm}$ thick layer of HAp on the crystal surface has a theoretical areal mass nearly three orders of magnitude higher $\left(0.32 \mu \mathrm{cm}^{-2}\right)$ than the sensitivity of the sensor. The mass change from the flat QCM sensor surface can be estimated from the change in the crystal's resonance frequency using the Sauerbrey equation, which states that a drop in the resonant frequency is directly proportional to an increase in areal mass. ${ }^{24}$ Changes in energy dissipation, less relevant to this work, provide a measure of energy losses in the system and contain information about the viscoelastic properties of soft films. ${ }^{25}$

While the majority of research on HAp that uses the QCM is on its growth (e.g., biomineralization ${ }^{26,27}$ ), only a few papers deal with the dissolution of HAp. For example, a commercially available nano-HAp-coated gold crystal was used as an in vitro model for monitoring of dental enamel erosion by citric ccid $^{28}$ and the protective effects of salivary films and polyelectrolytes. ${ }^{29}$ Commercially available HAp-coated QCM sensors have a relatively high cost, limited reusability and a denser microstructure than hard calcinosis, making them less suitable models for chelation therapy. ${ }^{29}$

While QCM sensors have previously been coated by methods such as electrolysis, ${ }^{30}$ they are more commonly coated by electrophoretic deposition (EPD), with the deposits then used as a model for stain removal ${ }^{31}$ or erosion in teeth, ${ }^{32}$ or 
protein adsorption on bone. ${ }^{33-35}$ EPD is a process that consists of two parts: electrophoresis (the motion of charged particles in a suspension under an electric field) and deposition (the coagulation of particles to a dense mass). ${ }^{36}$ During EPD, the chemical properties such as stoichiometry and phase composition are maintained, and the thickness and density of deposition can be tuned by parameters such as deposition duration and applied field. ${ }^{37}$

This current work establishes an in vitro assay to quantify and compare the effectiveness of chelators in the dissolution of calcinosis. The method development consisted of three steps. First, we assessed the potential of four types of synthetic HAp to act as proxies for hard calcinosis by comparing their dissolution behaviors. From this, we identified a suitable in vitro dissolution model for hard calcinosis. Second, we used the in vitro model to study dissolution performances with two wellestablished calcium chelators. This step has enabled us to both develop a data analysis strategy and establish whether our approach produces reliable results. Third, we adapted pharmaceutical dissolution testing methodology and performed tests from the second step using a HAp tablet as an in vitro model of calcinotic deposit. This step enabled us to validate our QCMbased approach against the "gold standard" for in vitro dissolution studies, identifying advantages and limitations for both methods.

\section{Experimental}

\section{Materials and reagents}

Gold-coated QCM crystals (QSX301, AT-cut, $14 \mathrm{~mm}$ diameter, $4.95 \pm 0.05 \mathrm{MHz}$ fundamental) were purchased from QSense. Hydroxyapatite (product code 04238 , lot number $\mathrm{SZBC} 2830 \mathrm{~V}$ ), calcium acetate monohydrate $\left[\mathrm{Ca}\left(\mathrm{CH}_{3} \mathrm{COO}\right)_{2} \cdot \mathrm{H}_{2} \mathrm{O}\right]$, calcium nitrate tetrahydrate $\left[\mathrm{Ca}\left(\mathrm{NO}_{3}\right)_{2} \cdot 4 \mathrm{H}_{2} \mathrm{O}\right]$, ammonium phosphate dibasic $\left[\left(\mathrm{NH}_{4}\right)_{2} \mathrm{HPO}_{4}\right]$, and $N, N_{,} N^{\prime}, N^{\prime}-$ tetraethylethylenediamine (TEEDA) were purchased from Sigma-Aldrich. Orthophosphoric acid $\left(\mathrm{H}_{3} \mathrm{PO}_{4}, 85 \%\right)$, sodium hydroxide $(\mathrm{NaOH})$, hydrochloric acid $(\mathrm{HCl}, 37 \%)$, aqueous ammonia $(35 \%)$, absolute ethanol, nitric acid $\left(\mathrm{HNO}_{3}, 70 \%\right)$, and ethylenediaminetetraacetic acid disodium salt dihydrate (EDTA) were purchased from Fisher Scientific. Anhydrous citric acid was purchased from Acros Organics. $N$-(2-hydroxyethyl)piperazine- $N$ '-(2-ethanesulfonic acid) (HEPES) was purchased from Formedium. Hydrogen peroxide $\left(30 \%, \mathrm{H}_{2} \mathrm{O}_{2}\right)$ was purchased from Merck. All reagents and non-aqueous solvents were used as received without further purification. Water was purified to a resistivity of $18.2 \mathrm{M} \Omega \mathrm{cm}$ at $25^{\circ} \mathrm{C}$ (Milli-Q). EDTA and citrate solutions with different concentrations (equivalence: $1 \mathrm{~g} \mathrm{~L}^{-1} \mathrm{EDTA}=3.4 \mathrm{mM}, 1 \mathrm{~g} \mathrm{L^{-1 }}$ citrate $=5.2 \mathrm{mM}$ ) used in the dissolution studies were buffered at $\mathrm{pH} 7.4$ (at $37^{\circ} \mathrm{C}$ ) with $0.1 \mathrm{M}$ HEPES. HEPES has a $\mathrm{p} K_{\text {a }}$ close to physiological $\mathrm{pH}$ values and contains no phosphate, which could interfere with both the dissolution process and subsequent elemental analysis. The $\mathrm{pH}$ of the buffered chelator solutions was reset to 7.4 by titrating with aqueous $1 \mathrm{M} \mathrm{NaOH}$.

The hard calcinotic deposits used for method validation came from three patients with the limited cutaneous subtype of SSc (two female, one male, age range 55 to 71 years), all with well-established disease (duration of Raynaud's phenomenon range 16 to 23 years). The three samples were obtained by surgical debulking. Sample color ranged from white to yellow to brown (Fig. S2). Patient data, indexed to internal sample codes, and an X-ray image of the one calcinosis sample before excision are given in section $\mathrm{S} 1$ of the supplementary information. The collection of the calcinosis samples was approved by the National Research Ethics Service (NRES) Committee North West (14/NW/0132) and the patients signed an informed consent form.

\section{Preparation and characterization of hydroxyapatites}

In addition to the commercially available HAp (denoted HApO), three additional HAp powders were prepared following literature methods. ${ }^{38}$ In brief, $\mathrm{HAp} 1$ was prepared by dropwise addition $\mathrm{H}_{3} \mathrm{PO}_{4}$ solution $(85 \%, 0.554 \mathrm{~mL}, 8.1 \mathrm{mM})$ into $\mathrm{Ca}(\mathrm{OH})_{2}(1.00 \mathrm{~g}, 13.5 \mathrm{mM})$ in $40 \mathrm{~mL}$ water solution. For HAp2, $\left(\mathrm{NH}_{4}\right)_{2} \mathrm{HPO}_{4}(2.00 \mathrm{~g}, 15.1 \mathrm{mM})$ was dissolved in $25 \mathrm{~mL}$ water. A second solution was prepared by dissolving $\mathrm{Ca}\left(\mathrm{CH}_{3} \mathrm{COO}\right)_{2} \cdot \mathrm{H}_{2} \mathrm{O}(4.45 \mathrm{~g}, 25.2 \mathrm{mM})$ in $60 \mathrm{~mL}$ water, followed by adding $3.0 \mathrm{~mL}$ ammonia solution and $40 \mathrm{~mL}$ water. The second solution was added dropwise to the first, followed by heating to $40^{\circ} \mathrm{C}$ for $3 \mathrm{~h}$. For $\mathrm{HAp} 3, \mathrm{Ca}\left(\mathrm{NO}_{3}\right)_{2} \cdot 4 \mathrm{H}_{2} \mathrm{O}(9.44 \mathrm{~g}, 40.0 \mathrm{mM})$ was dissolved in $35 \mathrm{~mL}$ water followed by adding $1.2 \mathrm{~mL}$ ammonia solution and $35 \mathrm{~mL}$ water. A second solution was prepared from $\left(\mathrm{NH}_{4}\right)_{2} \mathrm{HPO}_{4}(3.17 \mathrm{~g}, 24.0 \mathrm{mM})$ dissolved in $60 \mathrm{~mL}$ water followed by the addition of $30 \mathrm{~mL}$ ammonia solution and $40 \mathrm{~mL}$ water. The second solution was added dropwise into the first, followed 
by heating to reflux for $1 \mathrm{~h}$. Finally, all the HAp reaction mixtures were centrifuged and washed with water three times before drying in oven at $70^{\circ} \mathrm{C}$ for a week and ground in an agate mortar.

Attenuated total reflection Fourier-transform infrared (ATR-FTIR) spectra of powder samples were acquired using a Bruker Alpha-P run in air with $4 \mathrm{~cm}^{-1}$ resolution. Raman was determined using a Renishaw inVia, with a $633 \mathrm{~nm}$ excitation laser. Powder X-ray diffraction (PXRD) plots was acquired using PANalytical X'pert modular powder diffractometer with a copper anode X-ray source at $50 \mathrm{kV}$ and $40 \mathrm{~mA}$. The surface area was calculated by the Brunauer-Emmett-Teller (BET) method using a Micromeritics Gemini V Surface Area and Pore Size Analyzer. X-ray photoelectron spectra (XPS) were

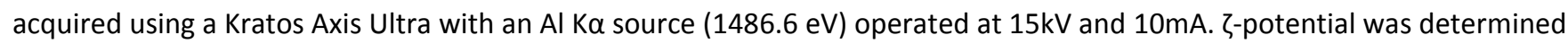
using Malvern Zetasizer Nano S. Aggregate size was determined using Malvern Mastersizer 3000. Deposit microstructure was determined by scanning electron microscopy (SEM) using a Hitachi S-3000N with a tungsten hairpin filament emission gun at an accelerating voltage of $5 \mathrm{kV}$; samples were prepared by dusting the solid sample on a conductive carbon tab. The calcium and phosphorous concentrations in the supernatant fluid in the QCM cell were measured by inductively coupled plasma mass spectrometry (ICP-MS, Agilent $7500 \mathrm{cx}$ ) after diluting them in $2 \%(\mathrm{w} / \mathrm{v})$ aqueous $\mathrm{HNO}_{3}$. Thermogravimetric analysis (TGA) was determined using TA Instruments Q500 in an $\mathrm{N}_{2}$ atmosphere with the ramp rate of $10{ }^{\circ} \mathrm{C} \mathrm{min}^{-1}$.

\section{Electrophoretic deposition}

Sensor surfaces were cleaned by immersing the sensors in a 5:1:1 (v:v:v) mixture of water, aqueous ammonia solution and aqueous hydrogen peroxide solution at $75^{\circ} \mathrm{C}$ for 5 minutes, followed by UV/ozone treatment for 15 minutes, following Q-Sense protocols. EPD of HAp was carried out following the procedure from Monkawa and co-workers. ${ }^{34} \mathrm{~A}$ modified QSense QEM401 module was adapted for EPD, with the gold surface acting as the cathode and the platinum plate acting as the anode. HAp powders were dispersed in ethanol $(1 \%(w / v))$, then injected into the module by a syringe. A field of $100 \mathrm{Vcm}^{-1}$ was applied (16V DC input, $0.16 \mathrm{~cm}$ separation fixed by an Viton o-ring) for $5 \mathrm{~min}$, followed by a brief ultrasonic treatment in ethanol to remove the loosely adhered HAp. The obtained HAp-coated crystal was left to dry in air at room temperature for $1 \mathrm{~min}$. Deposit masses ranged from 0.3-18 $\mu \mathrm{g}$.

\section{QCM dissolution measurements and analysis}

The freshly prepared HAp-coated crystal was transferred into a custom-built open QCM-D cell with a 8.2mm diameter cylindrical hole concentric with the crystal (nominal volume $0.5 \mathrm{~mL}$ ) and connected to the QCM-D (E1, Q-Sense) running QSoft version 2.5.21.694. The integrated Peltier device and an external water bath were used to maintain the temperature of the cell at $37^{\circ} \mathrm{C}$. HEPES buffer $(200 \mu \mathrm{L})$ was transferred into the cell through the hole, and a flat baseline was obtained after typically an hour of equilibration. Then, $10 \mu \mathrm{L}$ aliquots of buffered test solutions were added into the cell every $5 \mathrm{~min}$ for a total of 10 times for each experiment. The doses of chelator were chosen empirically to produce a frequency change that was above the limit of detection for the sensor and would dissolve no more than about of third of the total material on the surface with a single addition. This frequency response always stabilized within $5 \mathrm{~min}$ for citrate and EDTA aliquot concentrations $\leq 0.4 \mathrm{~g} \mathrm{~L}^{-1}$; the effects of higher concentrations are listed in the SI (Sections S4.1-S4.3). The endpoint (where all of the strongly bound HAp was removed) was established by adding two more aliquots of concentrated buffered test solutions where no more change of frequency response can be found. The final supernatant solution in the cell was collected for calcium and phosphorous analysis. Each experimental condition was tested at least 3 times.

The mass of the dissolved HAp was estimated using the simplified Sauerbrey equation: ${ }^{24}$

$$
\Delta m=-C \Delta f_{N} / N
$$

where $\Delta m$ is the dissolved mass, $C$ is a constant equal to $17.9 \mathrm{ng} \mathrm{cm}^{-2} \mathrm{~Hz}^{-1}, \Delta f_{N}$ is the frequency response associated with the corresponding harmonic number $N$. The seventh harmonic was used for data analysis, because of its moderate penetration depth and low sensitivity to mounting effects. ${ }^{39}$ Unscaled frequency responses are plotted in this work to make the method transferrable to other QCM systems. (The convention used in the Q-Sense software is to report a scaled frequency response $\left(\Delta f_{N} / N\right)$ to make it easier to compare the responses from several harmonics.) The active surface area of the sensor was assumed to be $0.80 \mathrm{~cm}^{2} .{ }^{40}$

Fei, Gallas et al. 
The frequency response versus time for each dissolution measurement was normalized by dividing by the final frequency change. The response from the first $10 \mathrm{~s}$ after the chelated was added was disregarded to allow the supernatant solution to homogenize. A time constant for each dissolution experiment was extracted from the subsequent $10 \mathrm{~s}$ (EDTA) or $30 \mathrm{~s}$ (citrate) of the normalized response by fitting to a first-order exponential. The method for determining outliers is discussed in the SI (Section S3).

\section{Manufacturing of hydroxyapatite tablets}

A single-punch Minipress MII (Riva Europe Ltd, UK) with manual feeding was used to produce HAp tablets via direct compression of freeze-dried HAp1 powder. Compression force in the tablet press was adjusted manually and a batch of tablets was considered suitable by passing both the disintegration and friability tests. ${ }^{41}$ The batch of tablets passed the disintegration test when none of the six randomly selected HAp tablets disintegrated within $15 \mathrm{~min}$ at $37^{\circ} \mathrm{C}$ while incubating in a Tablet Disintegration Tester ZT 31 (Copley Scientific, UK). The batch of tablets passed friability test when the mass loss of 20 randomly selected tablets after 100 cycles in Friability Tester (Copley Scientific, UK) was $\leq 1 \%$. The tablets were cylindrical, with beveled edges, $(9.57 \pm 0.01) \mathrm{mm}$ in diameter, $(2.4 \pm 0.2) \mathrm{mm}$ thick, with a mass of $(0.19 \pm 0.01) \mathrm{g}$ and hardness $\left(P_{\max }\right)$ of $(7.1 \pm 1.7) \mathrm{kg}$ (Tablet Hardness Tester TBF 1000, Copley Scientific).

\section{Pharmaceutical dissolution testing}

Dissolution of HAp tablets in chelator solutions was tested with a Dissolution Tester DIS 8000 (Copley Scientific, UK). Each vessel was filled with $750 \mathrm{~mL} 10 \mathrm{mM}$ HEPES buffer ( $\mathrm{pH} 7.4$ at RT), pre-warmed to $37^{\circ} \mathrm{C}$ and stirred with paddles at $60 \mathrm{rpm}$. One HAp tablet per vessel was added and incubated for $10 \mathrm{~min}$, followed by addition of $100 \mathrm{~mL}$ chelator concentrate and three rinses with $50 \mathrm{~mL}$ buffer at $37^{\circ} \mathrm{C}$ (total volume: $900 \mathrm{~mL}$ ). Six $10 \mathrm{ml}$ samples were collected every hour. Each sample collection was followed by addition of $10 \mathrm{~mL}$ top-up solution in order to keep the chelator concentration and volume constant. Subsequently, each sample was filtered through a $0.22 \mu \mathrm{m}$ filter (Whatman) and quantified for calcium and phosphorous using inductively coupled plasma optical emission spectroscopy (ICP-OES, Thermo iCap 6300). The chelator concentrate and top-up solutions were composed of $10 \mathrm{mM}$ HEPES, chelator (citric acid or EDTA) at relevant concentrations and $\mathrm{NaOH}$ and/or $\mathrm{HCl}$ for adjusting the $\mathrm{pH}$ to 7.4. Dissolution of $\mathrm{HAp}$ tablet in each chelator solution was studied in triplicate. Deionized water $\left(18.2 \mathrm{M} \Omega \mathrm{cm}\right.$ at $\left.25^{\circ} \mathrm{C}\right)$ was used to prepare all solutions and glassware throughout the experiments.

Calcium and phosphorous concentrations were expressed as HAp based on the following relationship: 1 mol calcium = $100.5 \mathrm{~g} \mathrm{HAp}$ and $1 \mathrm{~mol}$ phosphorous $=167.4 \mathrm{~g} \mathrm{HAp}$, and plotted against time for each chelator concentration. Error bars for each time point are equal to the population standard deviation $(n=3)$ calculated as 'STDEV.P' function in Microsoft Excel.

\section{Results and discussion}

The physicochemical characterization of the synthetic HAp samples is detailed in the SI (Section S2). In brief, the synthetic samples were predominantly calcium-deficient carbonated HAp, based on XPS elemental analysis (Figs. S3 and S4, Table S2) and vibrational spectroscopy (Figs. S5 and S6), with trace amounts of amorphous material, based on powder X-ray diffraction (Fig. S7). The Raman spectra (Fig. S6) did not show any signals characteristic of amorphous calcium phosphate $\left(945 \mathrm{~cm}^{-1}\right)$ or octacalcium phosphate $\left(955 \mathrm{~cm}^{-1}\right) .{ }^{42}$ Samples produced by the acetate route (HAp2) showed a greater mass loss by thermogravimetric analysis (Fig. $\mathrm{S} 8$ and some evidence of residual acetate, based on FT-IR (Fig. S5). Median hydrodynamic diameter of the particles ranged from 2-6 $\mu \mathrm{m}$ based on dynamic light scattering (Table S3). The BET surface area of the samples ranged from $60-100 \mathrm{~m}^{2} \mathrm{~g}^{-1}$, with the corresponding calculated particle diameters ranged from 20-30 $\mathrm{nm}$, which were in accordance with the grain sizes determined by XRD result (Table S3). The magnitude of the $\zeta$-potential of all the samples between pH 5 and 9 was below $25 \mathrm{mV}$ (Fig. S9). Consistent with this, visible-light and scanning electron micrographs (Figs. S10 and S11) and Raman maps (Fig. S12) showed the presence of aggregates $>10 \mu \mathrm{m}$ among the sparse deposits formed by EPD. The images from the HAp samples were indistinguishable from those from pulverized hard calcinosis (Figs. S10E, S11E, S12I\&J). Overall, the synthetic HAp samples were similar to hard calcinosis in chemical composition ${ }^{19,43-45}$ and mesoporosity. ${ }^{46}$ 


\section{Quartz crystal microbalance assay of chelation-based calcinosis treatments}

The QCM measurements plotted in Figure 1A demonstrate typical traces for positive and negative controls. The positive controls show the dissolution of commercial HAp (HApO) in two calcium chelators, citrate (cyan) and EDTA (dark red). A baseline response was observed for the three negative controls: excluding HAp but including citrate (black); including HAp but excluding the citrate (pink), and using the EDTA analog TEEDA (purple). TEEDA has a similar chemical structure to EDTA except that TEEDA does not have the carboxylic moieties to sequester $\mathrm{Ca}^{2+}$. Only the positive controls (citrate and EDTA) showed a monotonic increase in steady-state frequency (i.e., a regular decrease in mass) with chelator concentration that approaches a limiting value $\left(\Delta f_{\infty}\right)$. Each trace showed a negative frequency change in the first $5-10 \mathrm{~s}$ after each aliquot addition (Figure 1B), regardless of whether chelator was added, hence this range was excluded from kinetic analyses. The TEEDA and "-HAp, +citrate" negative controls showed a small decrease in frequency over the length of the measurement that was consistent with an increase in density of the fluid above the QCM sensor. ${ }^{47}$
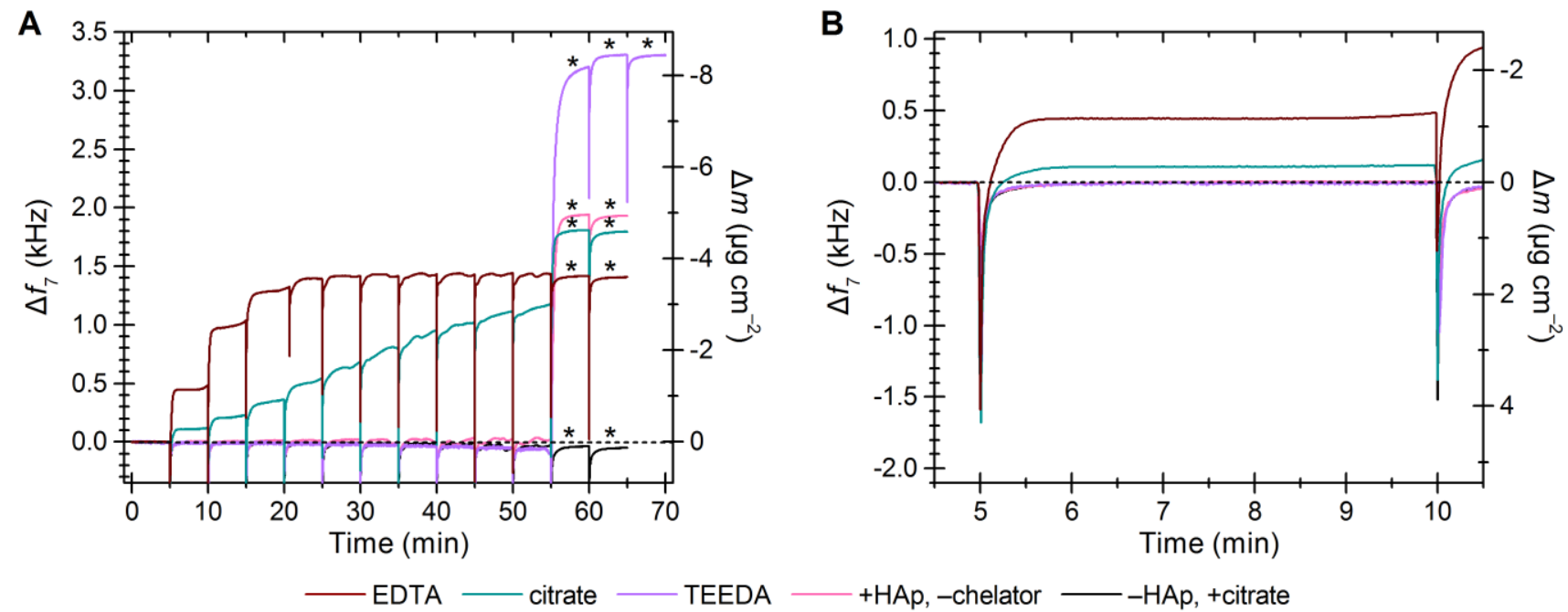

Figure 1. Representative QCM-D frequency responses from the dissolution of electrophoretically deposited commercial hydroxyapatite (HAp0). A Comparison of the mass changes on addition of buffered solutions containing a $\mathrm{Ca}^{2+}$ chelator (EDTA or citrate) and three negative controls (additions of non-chelating TEEDA, chelator-free buffer, or buffered citrate to a HAp-free surface). B Expansion of panel $A$ around the first addition to illustrate the initial transient response. Asterisks mark where concentrated chelator solution was used to dissolve the remaining HAp from the surface at the end of the measurement to determine the initial mass of HAp on the surface. The lefthand $y$-axes represent measured change in resonant frequency and the right-hand $y$-axes represent change in hydrated mass of material on the surface based on the Sauerbrey equation. Conditions: $37^{\circ} \mathrm{C}, 10 \mu \mathrm{L}$ additions, $0.4 \mathrm{~g} \mathrm{~L}^{-1}$ chelator $\left(*=40 \mathrm{~g} \mathrm{~L}^{-1}\right), 0.1 \mathrm{M} \mathrm{HEPES} \mathrm{pH} \mathrm{7.4.}$

Unsurprisingly, adding higher concentrations of chelator removed a greater fraction of a HAp deposit (Figure 2). The plots also show that fewer moles of EDTA than citrate were required to completely remove the deposits. Figure 3 compares the frequency changes recorded $5 \mathrm{~min}$ after the addition of chelators to the number of moles of chelator added. The slope of the line for EDTA is $(6.5 \pm 0.5)$ times higher than that for citrate: $(75.3 \pm 3.9) \mathrm{g}$ HAp per mol EDTA versus $(11.6 \pm 0.6) \mathrm{g}$ HAp per mol citrate. The amount of $\mathrm{Ca}^{2+}$ chelated by EDTA is sub-stoichiometric based on these estimates (100.46 $\mathrm{g} \mathrm{HAp} \mathrm{per} \mathrm{mol}$ calcium). The difference in the chelating capacity of EDTA compared to citrate can be attributed to EDTA's markedly higher $\mathrm{Ca}^{2+}$ binding strength $\left(\mathrm{p} K_{\mathrm{D}}=10.5\right.$ for $[\mathrm{Ca} \mathrm{EDTA}]^{2-48} \mathrm{vs.} 3.2$ for $\left[\mathrm{Ca}\right.$ citrate] ${ }^{-49}$ ). Also, the calcium-citrate complex is weaker than other insoluble complexes (e.g., $\mathrm{p} K \mathrm{SP}=6.6$ for $\mathrm{CaHPO}_{4} \cdot 2 \mathrm{H}_{2} \mathrm{O}$ ). ${ }^{50}$ Although to the best of our knowledge, there is no report on the comparison between EDTA and citrate in chelating HAp at physiological $\mathrm{pH}$, a number of researchers have shown that EDTA has better chelation capacity than citrate towards different types of calcium and magnesium minerals. ${ }^{51,52}$ 
Quartz crystal microbalance assay of chelation-based calcinosis treatments

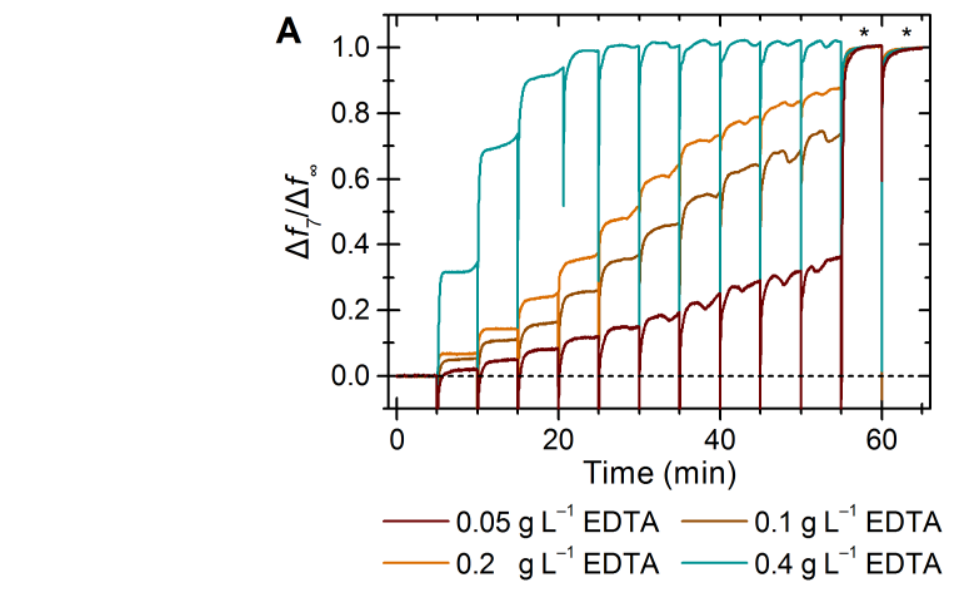

(1)

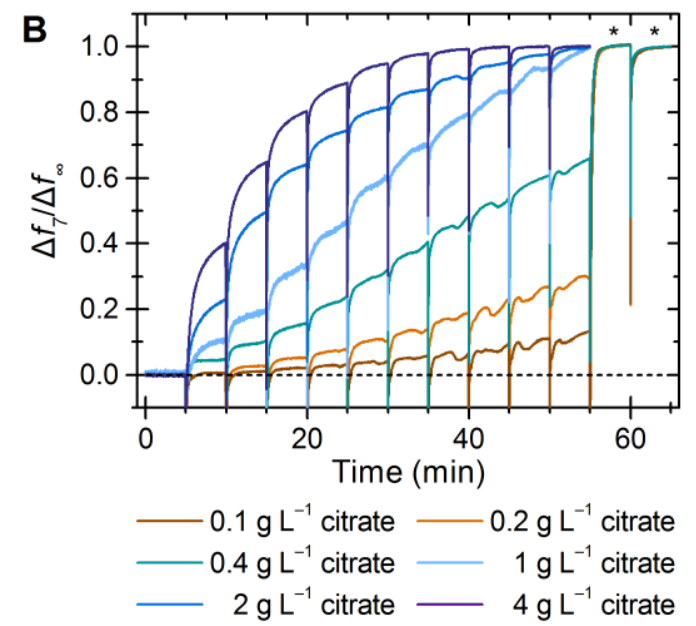

Figure 2. Plots showing the QCM-D frequency responses to the dissolution of commercial HAp (HApO) deposits in buffered solutions of varied concentrations of $\mathrm{Ca}^{2+}$ chelators: $\mathbf{A}$ EDTA and $\mathbf{B}$ citrate. Data are normalized to the final frequency change, $\Delta f_{\infty}$. Asterisks mark where $40 \mathrm{~g} \mathrm{~L}^{-1}$ chelator solution was used to dissolve the remaining HAp from the surface. Dissipation results from these data and QCM-D measurements that used higher chelator concentrations appear in the SI. Conditions: $37^{\circ} \mathrm{C}, 10 \mu \mathrm{L}$ additions, $0.1 \mathrm{M} \mathrm{HEPES} \mathrm{pH} \mathrm{7.4.}$

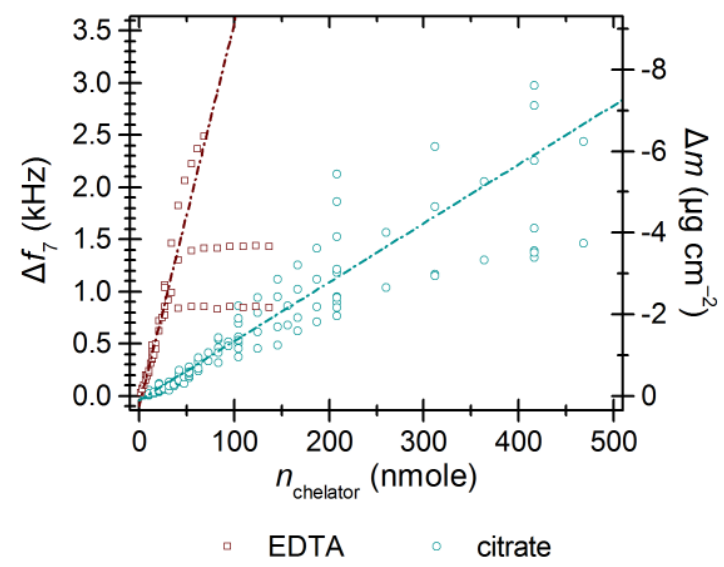

Figure 3. Comparison of chelation capacities of citrate and EDTA based on QCM-D analysis. Dash-dot lines are the linear least-squares fit to the data, excluding points where no additional HAp remained on the surface.

A qualitative analysis of the shape of the dissolution profile shows that the frequency response returns to a constant value much more quickly with EDTA than with citrate. Two assumptions were made for the kinetic analysis of the QCM results. The first assumption is that all the HAp surfaces will be rapidly saturated by chelator molecules during the entire dissolution process (at least 1.5 orders of magnitude above surface saturation levels, assuming a chelator footprint of $0.4 \mathrm{~nm}^{2}$ ). The second, related assumption is that the initial dissolution follows pseudo first-order reaction kinetics. Thus, the response was quantified as a first-order time constant for each chelator and each type of HAp. Figure 4A presents the mean rate constants for each combination of chelator and solid coating; all data points are shown in Figure S13. Pooling all the tests, the first-order rate constant was $(3.51 \pm 0.14) \mathrm{min}^{-1}$ for EDTA-meditated dissolution and $(8.47 \pm 0.48) \mathrm{min}^{-1}$ for citrate-meditated dissolution, that is, the EDTA dissolution rate was over twice as large. The differences in dissolution rate between EDTA and citrate were significant ( $p<0.01$, Welch's $t$-test, two tailed) for all HAp samples. There was no significant effect of chelator concentration on the initial rate, consistent with initial assumptions. There was also no correlation between the mass of the initial deposit and the dissolution rate constant. The HAp source had no significant effect on the time constant for EDTA, but significantly lower rate constants were observed for HAp2 and HAp3 dissolved in citrate $(p<$ 0.01). The normalization of the time constants by BET surface areas of HAp samples had no influence on the conclusions made above (data not shown). Applying the dissolution technique to hard calcinosis produced comparable QCM traces (Figure 4B) and statistically identical rate constants, indicating the equivalence of synthetic HAp samples and clinical hard calcinosis samples in dissolution testing. Table $S 4$ lists $p$ values for each pair of rate constants. For hard calcinosis samples, 
Quartz crystal microbalance assay of chelation-based calcinosis treatments visible-light and scanning electron microscopy (Figs. S10F and S11F) showed that some residue remained on the sensors even after the frequency response reached $\Delta f_{\infty}$.
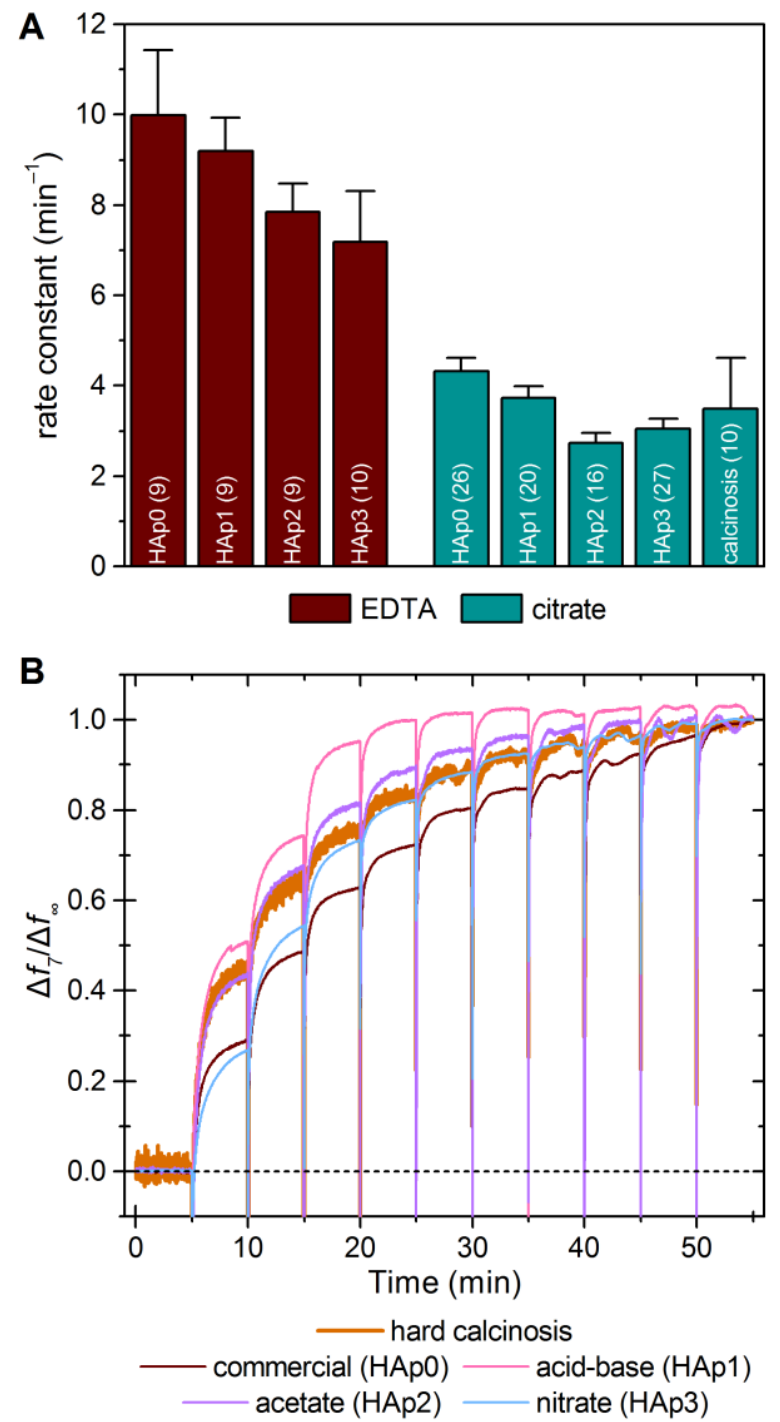

Figure 4. A First-order time constant for citrate and EDTA determined from at fit to the frequency change with time for the first addition of chelator. Number on bars: number of repeats for each group; error bars: standard error of the mean. B Representative QCM dissolution profile of hard calcinosis (sample C19) compared to those from the four synthetic HAp samples. Conditions: $37^{\circ} \mathrm{C}, 10 \mu \mathrm{L}$ aliquots of $2 \mathrm{~g} \mathrm{~L}^{-1}$ citrate in $0.1 \mathrm{M}$ HEPES pH 7.4.

Figure 5 presents the comparison of the mass of HAp derived from ICP-MS analysis to the mass determined from $\Delta f_{\infty}$ and the Sauerbrey equation. A linear fit to the data gives a slope of $(0.69 \pm 0.15)$, which is attributed to underestimation of the ICP-MS calculations and the overestimation of the QCM measurements. The ICP-MS may underestimate the mass because of the use of the nominal stoichiometry as an approximation of the carbonated, calcium-deficient samples as revealed in FTIR and XPS spectra (SI); this calcium deficiency also appears in the ICP-OES calcium and phosphorous analysis of dissolved HAp tablets. The QCM's mass response is also sensitive to mechanically coupled water, such as water adsorbed on or trapped between particles, which would lead to an overestimate of the adsorbed mineral mass. The magnitude of this effect is consistent with previous QCM measurements and models from Johannsmann and co-workers of adsorbed nanospheres. ${ }^{53}$ For many measurements, changes in the sensor's energy dissipation during dissolution (Section S4) are also consistent with Johannsmann's work: the $\Delta d$ values initially rise as space between particles opens up and allowing the particles to rock on the surface; then the values drop as the dissolution approaches completion. Furthermore, the spread of harmonics (Section S4.4) can be explained by the fact that each harmonic has a specific penetration depth; the lower 
harmonics sense a larger frequency increase (i.e., mass loss) due to the larger penetration depth than the higher harmonics. $^{39}$

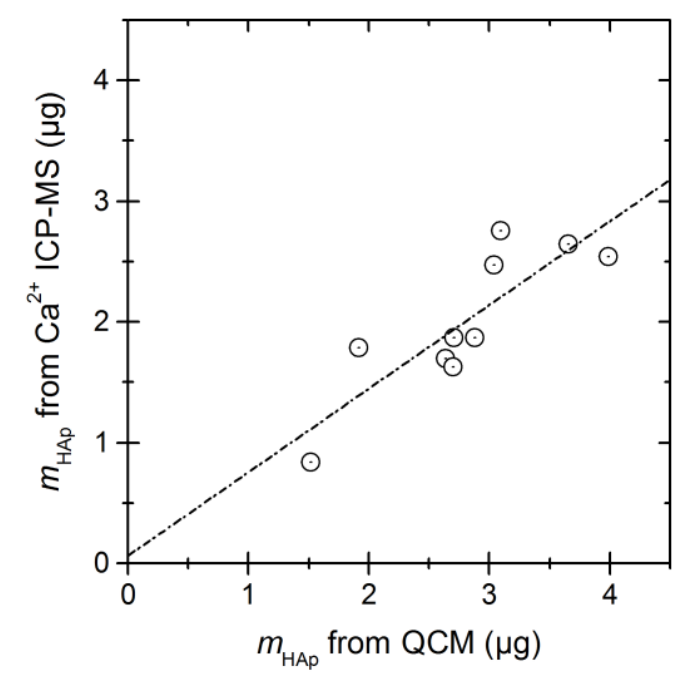

Figure 5. Correlation between the HAp masses determined by QCM and ICP-MS. The $x$-axis shows the QCM results where the mass of the dissolved HAp was calculated by the final frequency change and the Sauerbrey equation. The $y$-axis shows the ICP-MS results where the mass of HAp was calculated by quantifying $\mathrm{Ca}^{2+}$ in the supernatant and through the stoichiometric formula of HAp. The dash-dot line is a linear least-squares fit to the data $\left(r^{2}=0.69\right)$.

Having established the equivalence between synthetic HAp and hard calcinosis, pharmaceutical dissolution testing (PDT) was adapted to validate QCM approach against the "gold standard" methodology for in vitro dissolution studies. Usually, PDT is used to monitor drug release from various pharmaceutical formulations (e.g., tablets) into physiological buffers in order to estimate drug release in vivo. Our application measured release calcium and phosphorous from an HApcomposed tablet upon exposure to calcium chelators, assuming a HAp tablet to be a model for hard calcinosis. Direct powder compression avoided the addition of any additives in the tablet manufacturing process and therefore modeled calcinotic deposits more closely. Neither the HAp0 nor the HAp1 powders flowed well once inserted into the hopper of the tablet press, so manual feeding and compression were used. Only HAp1-based tablets were used for PDT because HAp0based tablets repeatedly failed the disintegration test. All experimental parameters of the PDT were selected to mimic physiological conditions in vivo, as per literature. ${ }^{41}$

Three concentrations of citrate and EDTA were studied by PDT (Figure 6A). As in the case of the QCM assays, a large excess of chelator was supplied ( $\geq 10 \mathrm{mmol}$ of chelator per g HAp). HAp dissolved more quickly in the higher concentration of both chelators in contrast to the concentration-independent behavior of the initial rates determined by QCM analysis. Incubation of a HAp tablet with $75 \mathrm{mM}$ citrate produced results that were statistically identical to $50 \mathrm{mM}$ citrate. EDTA was known to be a more effective calcium chelator, so a maximum concentration of 26 mM was used for PDT. Although the correlation coefficients for all the curves seem to be slightly higher based on phosphorous analysis than calcium analysis, the difference is not significant. Identical analyses based on ICP-OES of the phosphorous content of the solution appear in the SI (Fig. S23 and Tables S5 and S6).

Fei, Gallas et al. 
Quartz crystal microbalance assay of chelation-based calcinosis treatments

A

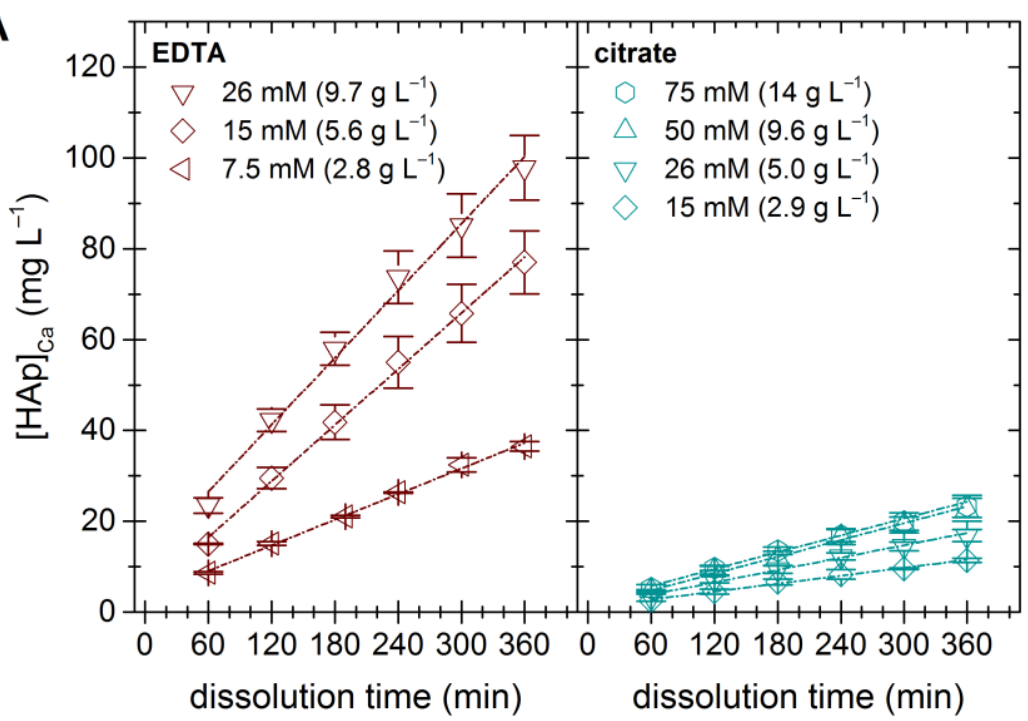

B

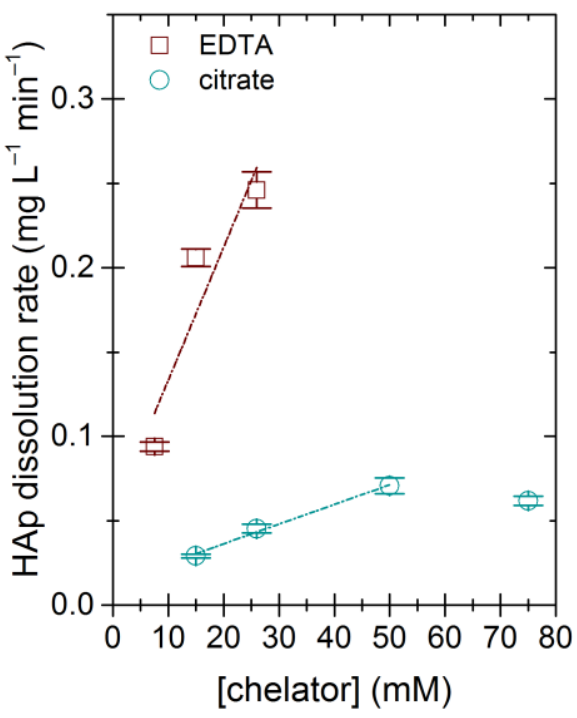

Figure 6. Plots of the dissolution of tablets of HAp produced by the acid-base route (HAp1) in three different concentrations of EDTA and citrate using PDT and ICP-OES quantification of $\mathrm{Ca}^{2+}$ in the solvent. A Plots of the variation in dissolved HAp concentration with time for three EDTA (left) and citrate (right) concentrations. B Analysis of dissolution rate based on first-order kinetics with respect to chelator concentration. Error bars represent population standard deviation ( $n=3)$. Conditions: $37^{\circ} \mathrm{C}, 10 \mathrm{mM} \mathrm{HEPES} \mathrm{pH} \mathrm{7.4.}$

The HAp dissolution from PDT were plotted assuming a first-order dependence on chelator concentration (Figure 6B). As for the QCM assay, chelators are assumed to saturate of the HAp surface. As with the QCM, EDTA was found to be a more effective dissolution agent than citric acid. The ratio of the apparent rate constant for EDTA to that from citrate is (6.7 \pm 2.7 ), much higher than the two-fold higher rate observed by QCM. The difference in rates between two techniques is a result of the longer measurement time used in PDT studies, so the effects of particle size and diffusion influence kinetic analysis, ${ }^{20}$ as well as the formation of other calcium phosphates with limited solubility. ${ }^{54}$

Table 1 summarizes the advantages and limitations of the QCM assay compared to PDT. The QCM assay is much faster: each run could take just $15 \mathrm{~min}$ by allowing $5 \mathrm{~min}$ each for equilibration, dilute chelator addition (to measure the rate constant) and concentrated chelator addition (to measure the total mass deposited). Thus, the method could be automated and adapted to high-throughput screening equipment (e.g., the Q-Sense Omega Auto system).

Table 1. Key advantages and limitations of QCM and PDT methods in assaying effectiveness chemicals to dissolve HAp.

\begin{tabular}{lcc} 
& EPD + QCM & tableting + PDT \\
\hline Analysis mass & $1-10 \mu \mathrm{g}$ & $\geq 10 \mathrm{mg}$ \\
Control over analysis mass & low & high \\
Range of samples that can be analyzed & + & $-{ }^{\mathrm{a}}$ \\
Single measurement precision & - & - \\
Single measurement accuracy & + & + \\
Real time kinetics monitoring & + & - \\
Analysis time & $0.25-2 \mathrm{~h}$ per run & $6-24 \mathrm{~h} \mathrm{per} \mathrm{run}$ \\
Test volume & low (<1 mL) & high (ca. $1 \mathrm{~L}$ ) \\
Requirement for $\mathrm{Ca}^{2+}$ quantification & only initially & each sample
\end{tabular}

Fei, Gallas et al. 


\section{Conclusion}

We have established that the combination of EPD and QCM can be used to differentiate the capacity and rate of two common chelators, EDTA and citrate, in dissolving HAp from various sources. We have demonstrated that HAp particles can be used as an in vitro model for hard calcinosis. Both QCM assays and PDT showed that EDTA was much faster than citrate at dissolving HAp, though the rate analysis from PDT produced a greater difference in rates. Rate constants determined by QCM were independent of chelator concentration, while those from PDT showed a first-order dependence. Although we describe method that is directly relevant to drug development for diseases associated with hydroxyapatite-based deposits (e.g., SSc, calcific tendonitis, pseudoxanthoma elasticum), this methodology could also be applied to conditions associated with other hard deposits, such as gout or pseudogout, and to studies in which HAp nanoparticles are used for dental and bone tissue engineering or drug delivery applications. ${ }^{55}$

\section{Supporting information}

Supporting information available: X-ray image and photographs of hard calcinosis samples information on the patients from whom the samples were excised; physicochemical and textural analysis of synthetic HAp samples (FTIR; Raman; X-ray photoelectron spectroscopy; powder X-ray diffraction; $\zeta$-potential; thermogravimetric analysis; dynamic light scattering; nitrogen porosimetry; visible-light microscopy, scanning electron microscopy and Raman maps of sensors coated with synthetic hydroxyapatite and calcinosis); box plots showing all calculated rate constants and pairwise tests of statistical significance; additional QCM-D data (other concentrations of chelators, extended dissolution runs, effect of harmonic number); plots of PDT data based on phosphorous analysis. In accordance with the University of Manchester's guidelines, the data are openly available from Mendeley Data (doi:10.17632/9tnr3t54wn.1); the DOI will be activated after acceptance. The draft version of the data, available to reviewers is available at https://data.mendeley.com/datasets/9tnr3t54wn/draft?a=27313f87-ed6f-478f-86d3-44a6b7676b63

\section{Acknowledgments}

The authors acknowledge funding from Scleroderma \& Raynaud's UK (SRUK, grant MU6) and the University of Manchester's School of Materials, and experimental support from Dr. Roberto Donno (Mastersizer), Mr. Michael Faulkner

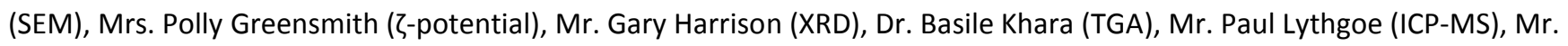
Martin Jennings and Mrs. Anne Davies (ICP-OES), Mrs. Joanne Manning (hard calcinosis sample collection), Dr. Ben Spencer (XPS), Dr. John Waters (surface area analysis), and Mr. Andrij Zadoroshnyj (Raman).

\section{Conflicts of interest}

The authors declare no conflicts of interest. 
Quartz crystal microbalance assay of chelation-based calcinosis treatments

\section{References}

(1) Chander, S.; Gordon, P. Soft Tissue and Subcutaneous Calcification in Connective Tissue Diseases. Curr. Opin. Rheumatol. 2012, 24, 158-164.

(2) Åkesson, A.; Wollheim, F. A. Organ Manifestations in 100 Patients with Progressive Systemic Sclerosis: A Comparison between the CREST Syndrome and Diffuse Scleroderma. Br. J. Rheumatol. 1989, 28, 281-286.

(3) Salazar, G. A.; Mayes, M. D. In A Visual Guide to Scleroderma and Approach to Treatment; Springer: 2014, p 89-96.

(4) Reiter, N.; El-Shabrawi, L.; Leinweber, B.; Berghold, A.; Aberer, E. Calcinosis Cutis: Part I. Diagnostic Pathway. J. Am. Acad. Dermatol. 2011, 65, 1-12.

(5) Herrick, A. L.; Gallas, A. J. Systemic Sclerosis-Related Calcinosis. Journal of Scleroderma and Related Disorders 2016, 1, 194-203.

(6) Reiter, N.; El-Shabrawi, L.; Leinweber, B.; Berghold, A.; Aberer, E. Calcinosis Cutis: Part II. Treatment Options. J. Am. Acad. Dermatol. 2011, 65, 15-22.

(7) Valenzuela, A.; Chung, L. Calcinosis: Pathophysiology and Management. Curr. Opin. Rheumatol. 2015, 27, 542-548.

(8) Lanigan, R. S.; Yamarik, T. A. Final Report on the Safety Assessment of EDTA, Calcium Disodium EDTA, Diammonium EDTA, Dipotassium EDTA, Disodium EDTA, TEA-EDTA, Tetrasodium EDTA, Tripotassium EDTA, Trisodium EDTA, HEDTA, and Trisodium HEDTA. Int. J. Toxicol. 2001, 21, 95-142.

(9) Scelza, M. F. Z.; da Silva Pierro, V. S.; Chagas, M. A.; da Silva, L. E.; Scelza, P. Evaluation of Inflammatory Response of EDTA, EDTA-T, and Citric Acid in Animal Model. Journal of Endodontics 2010, 36, 515-519.

(10) Blanusa, M.; Varnai, V. M.; Piasek, M.; Kostial, K. Chelators as Antidotes of Metal Toxicity: Therapeutic and Experimental Aspects. Curr. Med. Chem. 2005, 12, 2771-2794.

(11) Klein, R.; Harris, S. B. Treatment of Scleroderma, Sclerodactylia and Calcinosis by Chelation (EDTA). Am. J. Med. 1955, 19, 798-807.

(12) Davis, H.; Moe, P. J. Favorable Response of Calcinosis Universalis to Edathamil Disodium. Pediatrics 1959, 24, 780785.

(13) Winder, P. R.; Curtis, A. C. Edathamil in the Treatment of Scleroderma and Calcinosis Cutis. Arch. Dermatol. 1960, $82,732-736$.

(14) Fink, C. W.; Baum, J. Treatment of Calcinosis Universalis with Chelating Agent. Am. J. Dis. Child. 1963, 105, 390-392.

(15) Herd, J. K.; Vaughan, J. H. Calcinosis Universalis Complicating Dermatomyositis - Its Treatment with Na2EDTA. Report of Two Cases in Children. Arthritis Rheum. 1964, 7, 259-271.

(16) Lydon, C.; Lowe, T.; Withers, P.; Herrick, A.; O'Brien, P.; Winpenny, R. 239. Analysis and Dissolution of SSc-Related Calcinoses. Rheumatology 2014, 53, i149.

(17) Arbel, A.; Katz, I.; Sarig, S. Dissolution of Hydroxyapatite by Calcium Complexing Agents. J. Cryst. Growth 1991, 110, 733-738.

(18) Leroux, J. L.; Pernot, F.; Fedou, P.; Poubelle, P.; Bonnel, F.; Baldet, P.; Blotman, F.; Simon, L. Ultrastructural and Crystallographic Study of Calcifications from a Patient with CREST Syndrome. J. Rheumatol. 1983, 10, 242-246.

(19) Lin, S.-Y. Biochemical and Molecular Aspects of Spectral Diagnosis in Calcinosis Cutis. Expert Rev. Mol. Med. 2014, 16, e6 (17pp).

(20) Wu, M.-S.; Higuchi, W. I.; Fox, J. L.; Friedman, M. Kinetics and Mechanism of Hydroxyapatite Crystal Dissolution in Weak Acid Buffers Using the Rotating Disk Method. J. Dent. Res. 1976, 55, 496-505.

(21) Higuchi, W. I.; Cesar, E. Y.; Cho, P. W.; Fox, J. L. Powder Suspension Method for Critically Re-Examining the Two-Site Model for Hydroxyapatite Dissolution Kinetics. J. Pharm. Sci. 1984, 73, 146-153.

(22) Tucker, B. E.; Cottell, C. M.; Auyeungt, R. C. Y.; Spector, M.; Nancollas, G. H. Pre-Conditioning and Dual Constant Composition Dissolution Kinetics of Pulsed Laser Deposited Hydroxyapatite Thin Films on Silicon Substrates. Biomaterials 1996, 17, 631-637.

(23) Rodriguez-Pardo, L.; Rodríguez, J. F.; Gabrielli, C.; Perrot, H.; Brendel, R. Sensitivity, Noise, and Resolution in QCM Sensors in Liquid Media. IEEE Sens. J. 2005, 5, 1251-1257.

(24) Sauerbrey, G. Use of Vibrating Quartz for Thin Film Weighing and Microweighing. Z. Phys. 1959, 155, $206-222$. 
Quartz crystal microbalance assay of chelation-based calcinosis treatments

(45) Thompson, R. B.; Reffatto, V.; Bundy, J. G.; Kortvely, E.; Flinn, J. M.; Lanzirotti, A.; Jones, E. A.; McPhail, D. S.; Fearn, S.; Boldt, K. Identification of Hydroxyapatite Spherules Provides New Insight into Subretinal Pigment Epithelial Deposit Formation in the Aging Eye. Proc. Natl. Acad. Sci. U. S. A. 2015, 112, 1565-1570.

(46) Lydon, C.; Lowe, T.; Withers, P.; Herrick, A.; O'Brien, P.; Winpenny, R. What Are Systemic Sclerosis-Related Calcinoses Made of and Can We Dissolve Them? Clin. Exp. Rheumatol. 2014, 32, S43-S43.

(47) Voinova, M. V.; Rodahl, M.; Jonson, M.; Kasemo, B. Viscoelastic Acoustic Response of Layered Polymer Films at Fluid-Solid Interfaces: Continuum Mechanics Approach. Phys. Scr. 1999, 59, 391-396.

(48) Arena, G.; Musumeci, S.; Purrello, R.; Sammartano, S. Calcium- and Magnesium-EDTA Complexes. Stability Constants and Their Dependence on Temperature and Ionic Strength. Thermochim. Acta 1983, 61, 129-138.

(49) Walser, M. Ion Association. V. Dissociation Constants for Complexes of Citrate with Sodium, Potassium, Calcium and Magnesium lons. J. Phys. Chem. 1961, 65, 159-161.

(50) Gregory, T. M.; Moreno, E. C.; Brown, W. E. Solubility of CaHPO4.2H2O in System Ca(OH)2-H3PO4-H2O at 5, 15, 25, and $37.5^{\circ}$ C. J. Res. Natl. Bur. Stand., Sect. A 1970, 74A, 461-475.

(51) Pérez-Heredia, M.; Ferrer-Luque, C. M.; González-Rodríguez, M. P.; Martín-Peinado, F. J.; González-López, S. Decalcifying Effect of 15\% EDTA, 15\% Citric Acid, 5\% Phosphoric Acid and 2.5\% Sodium Hypochlorite on Root Canal Dentine. International Endodontic Journal 2008, 41, 418-423.

(52) Jordan, G.; Pokrovsky, O. S.; Guichet, X.; Schmahl, W. W. Organic and Inorganic Ligand Effects on Magnesite Dissolution at $100{ }^{\circ} \mathrm{C}$ and $\mathrm{pH}=5$ to 10 . Chem. Geol. 2007, 242, 484-496.

(53) Johannsmann, D.; Reviakine, I.; Richter, R. P. Dissipation in Films of Adsorbed Nanospheres Studied by Quartz Crystal Microbalance (QCM). Anal. Chem. 2009, 81, 8167-8176.

(54) Chow, L. C. In Octacalcium Phosphate; Chow, L. C., Eanes, E. D., Eds.; Karger: Basel, 2001; Vol. 18, p 94-111

(55) Bose, S.; Tarafder, S. Calcium Phosphate Ceramic Systems in Growth Factor and Drug Delivery for Bone Tissue Engineering: A Review. Acta Biomater. 2012, 8, 1401-1421. 
For Table of Contents Only

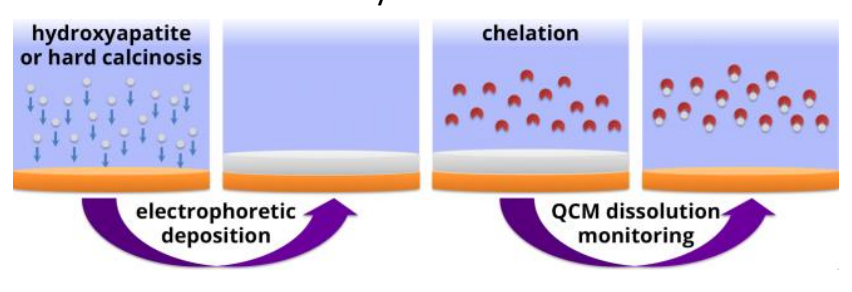



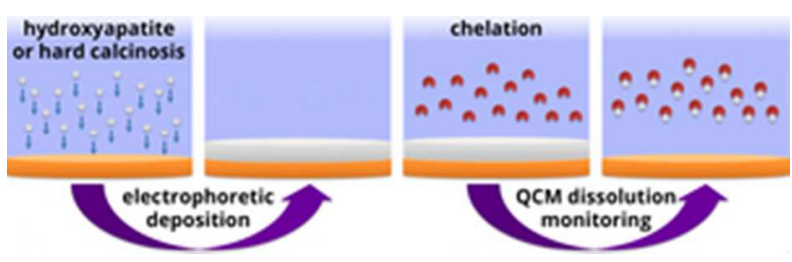

Table of contents graphic @ 600 dpi $25 \times 7 \mathrm{~mm}(300 \times 300$ DPI $)$ 

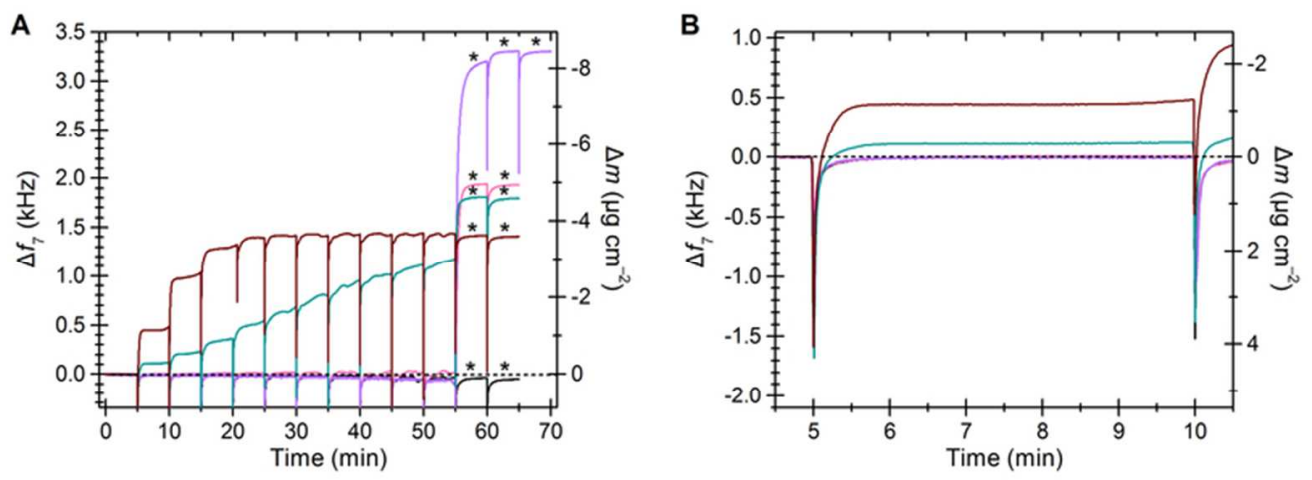

— EDTA — citrate — TEEDA — +HAp, -chelator - - HAp, +citrate

Figure $1 @ 600$ dpi

$68 \times 26 \mathrm{~mm}(300 \times 300 \mathrm{DPI})$ 

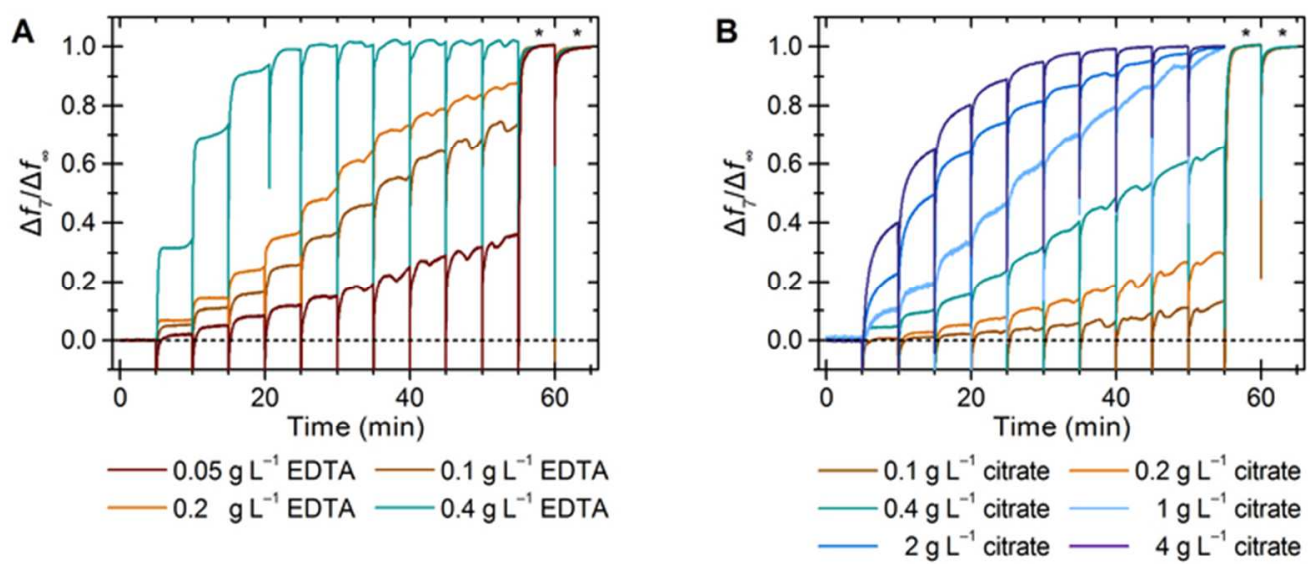

Figure $2 @ 600 \mathrm{dpi}$

$63 \times 27 \mathrm{~mm}(300 \times 300 \mathrm{DPI})$ 


1
2
3
4
5
6
7
8
9
10
11
12
13
14
15
16
17
18
19
20
21
22
23
24
25
26
27
28
29
30
31
32
33
34
35
36
37
38
39
40
41
42
43
44
45
46
47
48
49
50
51
52
53
54
55
56
57
58
60

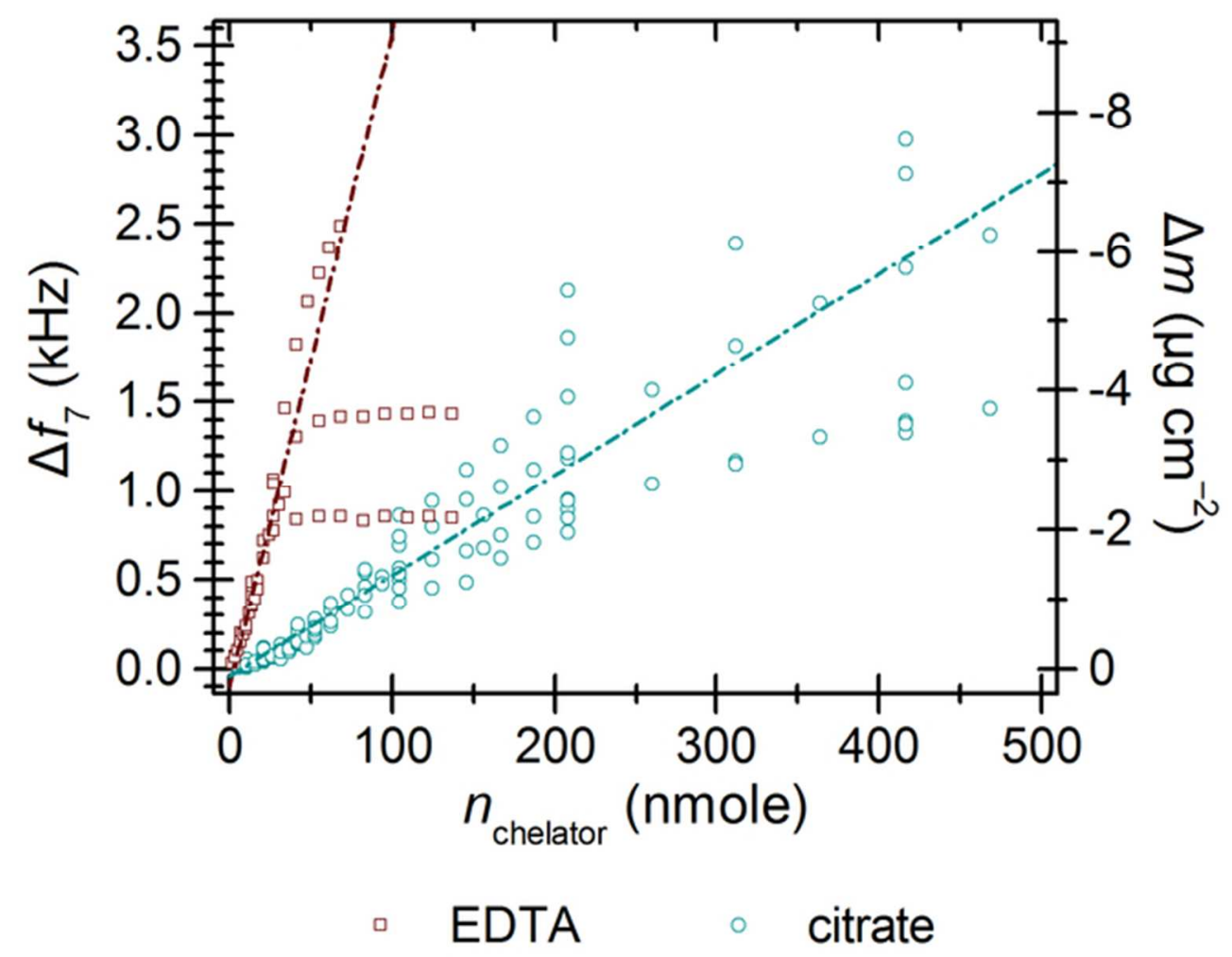

Figure $3 @ 600$ dpi

$56 \times 44 \mathrm{~mm}(300 \times 300$ DPI $)$ 

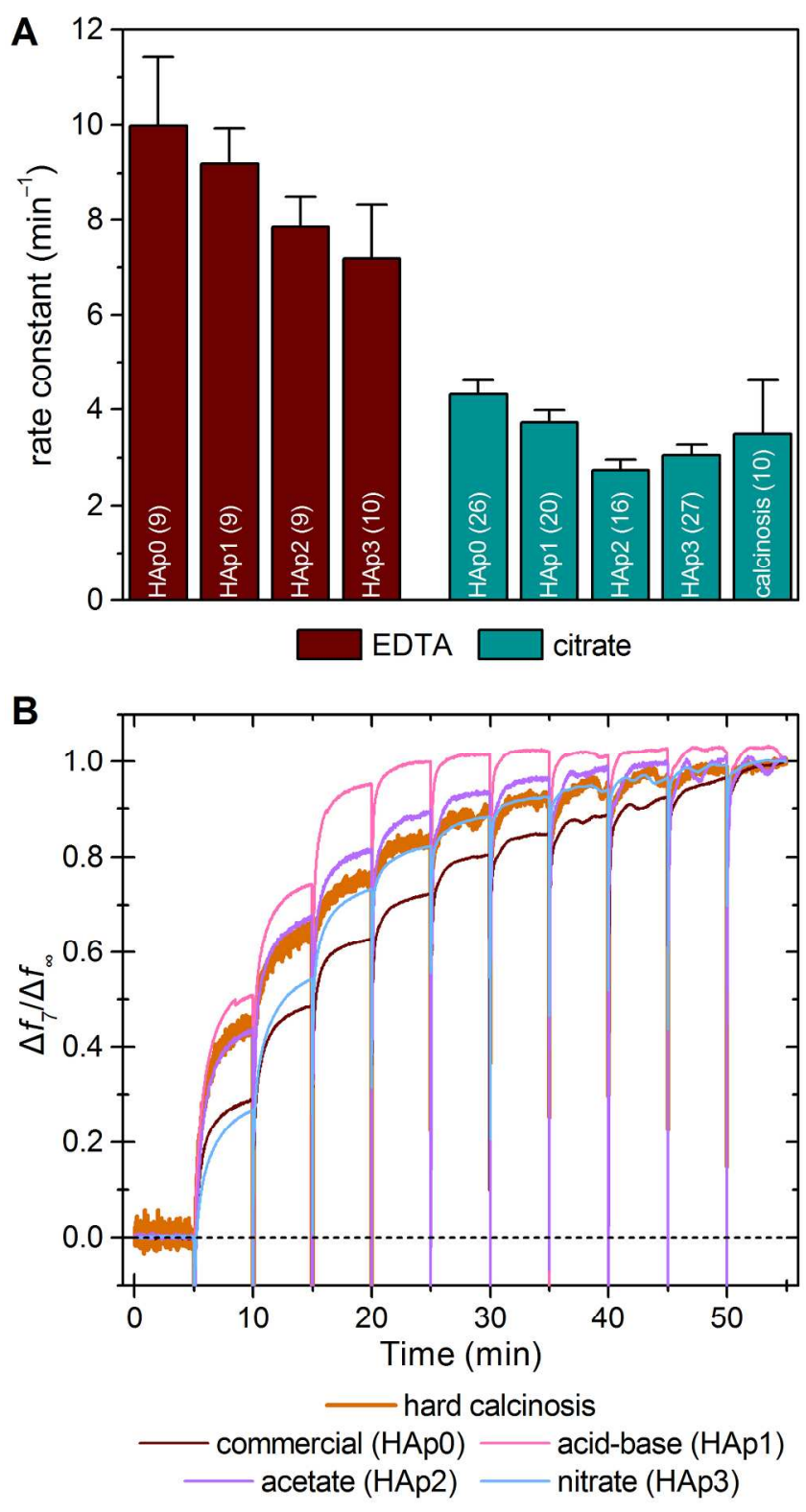

Figure $4 @ 600$ dpi $144 \times 271 \mathrm{~mm}(300 \times 300$ DPI $)$ 


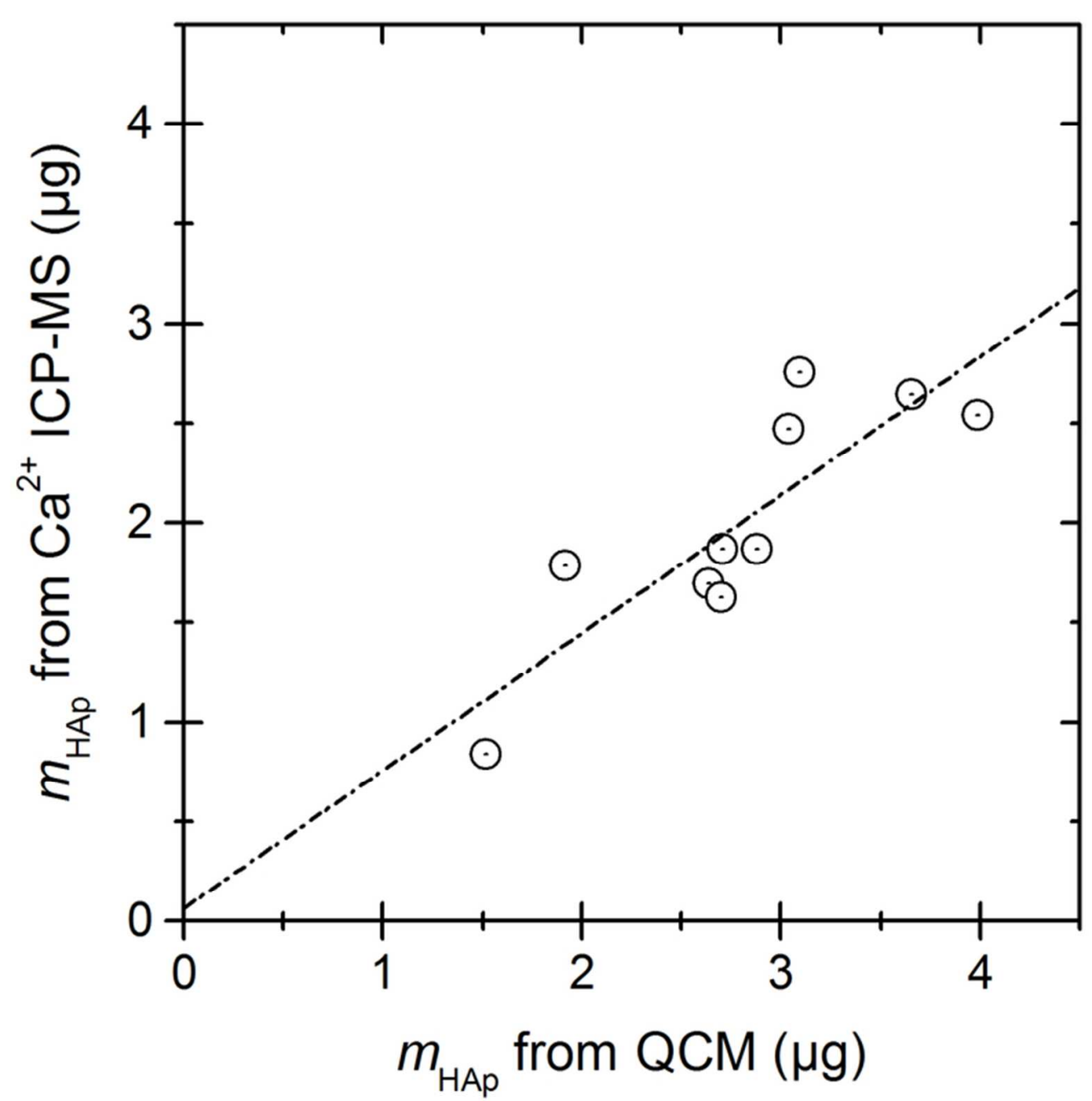

Figure $5 @ 600$ dpi

$66 \times 67 \mathrm{~mm}(300 \times 300$ DPI $)$ 
A

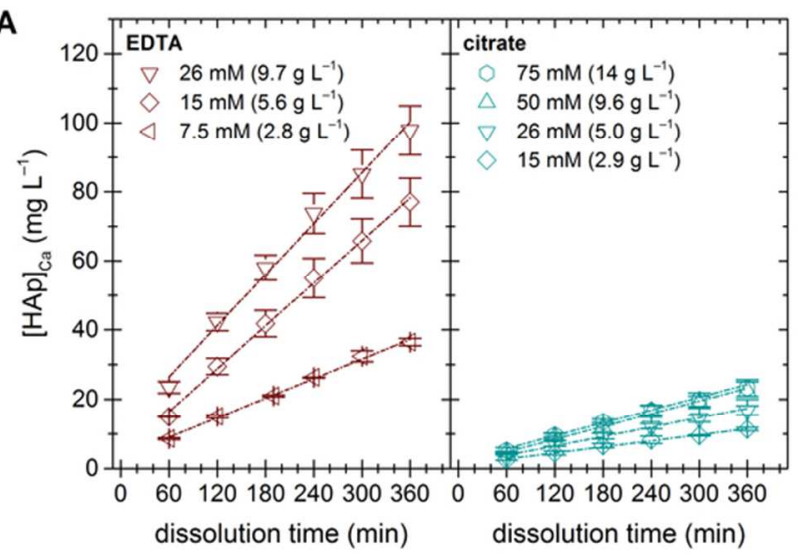

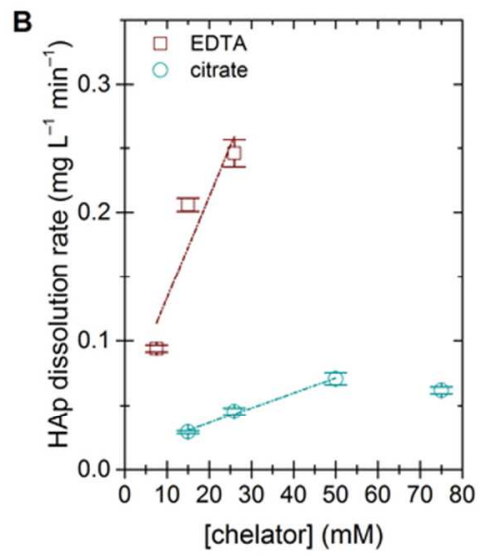

Figure $6 @ 600 \mathrm{dpi}$

$73 \times 31 \mathrm{~mm}(300 \times 300 \mathrm{DPI})$ 